\title{
SOCIEDADE DE CONTROLE
}

\author{
ROGÉRIO DA COSTA
}

\begin{abstract}
Resumo: Esse artigo trata de algumas diferenças entre as sociedades disciplinares e a sociedade de controle. Ele toma por base as reflexões do filósofo Gilles Deleuze sobre o trabalho de Michel Foucault. Aborda também as recentes tecnologias de controle e os mais recentes projetos do governo norte-americano para rastrear as ações de indivíduos no planeta.

Palavras-chave: sociedade de controle; código; modulação social.

Abstract: This article examines some of the differences among disciplinary societies and the society of control. It takes as its starting point the reflections of the philosopher Gilles Deleuze regarding the work of Michel Foucault. It also discusses the new technologies of control and the most recent projects of the United States government, capable of tracking the activities of individuals anywhere on the planet.

Key words: society of control; code; social modulation.
\end{abstract}

Não há necessidade de ficção científica para conceber um mecanismo de controle que forneça a cada instante a posição de um elemento em meio aberto, animal numa reserva, homem numa empresa (coleira eletrônica). Félix Guattari imaginava uma cidade onde cada um pudesse deixar seu apartamento, sua rua, seu bairro, graças ao seu cartão eletrônico, que removeria qualquer barreira; mas, do mesmo modo, o cartão poderia ser rejeitado tal dia, ou entre tais horas; o que conta não é a barreira, mas o computador que localiza a posição de cada um, lícita ou ilícita, e opera uma modulação universal

Gilles Deleuze (1990)

$\mathrm{N}$ um artigo intitulado "Post-Scriptum sobre as Sociedades de Controle", o filósofo Gilles Deleuze (1990) indicava alguns aspectos que poderiam distinguir uma sociedade disciplinar de uma sociedade de controle. As sociedades disciplinares podem ser situadas num período que vai do século XVIII até a Segunda Grande Guerra, sendo que os anos da segunda metade do século XX estariam marcados por seu declínio e pela respectiva ascensão da sociedade de controle. Seguindo as análises de Michel Foucault, Deleuze percebe no enclausuramento a operação fundamental da socieda- de disciplinar, com sua repartição do espaço em meios fechados (escolas, hospitais, indústrias, prisão...), e sua ordenação do tempo de trabalho. Ele chamou esses processos de moldagem, pois um mesmo molde fixo e definido poderia ser aplicado às mais diversas formas sociais. Já a sociedade de controle seria marcada pela interpenetração dos espaços, por sua suposta ausência de limites definidos (a rede) e pela instauração de um tempo contínuo no qual os indivíduos nunca conseguiriam terminar coisa nenhuma, pois estariam sempre enredados numa espécie de formação permanente, de dívida impagável, prisioneiros em campo aberto. O que haveria aqui, segundo Deleuze, seria uma espécie de modulação constante e universal que atravessaria e regularia as malhas do tecido social.

Deleuze sugere ainda que as sociedades disciplinares possuem dois pólos, "a assinatura que indica o indivíduo, e o número de matrícula que indica sua posição numa massa". Nas sociedades de controle, "o essencial não seria mais a assinatura nem um número, mas uma cifra: a cifra é uma senha (...) A linguagem digital do controle é feita de cifras, que marcam o acesso ou a recusa a uma informação" (Deleuze, 1990). A força dessa interpretação 
reside em um aspecto que gostaríamos de analisar neste artigo: a relação entre identidade pessoal e código intransferível (ou cifra, como diz Deleuze). A passagem de um a outro implica que os indivíduos deixam de ser, justamente, indivisiveis, pois passam a sofrer uma espécie de divisão, que resulta do estado de sua senha, de seu código (ora aceito, ora recusado). Além disso, as massas, por sua vez, tornam-se amostras, dados, mercados, que precisam ser rastreados, cartografados e analisados para que padrões de comportamentos repetitivos possam ser percebidos.

Para tentar compreender melhor essas distinções, e esclarecendo desde já que há muitas maneiras de se abordar a recente sociedade de controle e seus mecanismos (Hardt, 1998; Lessig, 1999; Rheingold, 2002; Shapiro, 1999), vamos abordar aqui a forma como os dispositivos de controle se ocupam de informações resultantes das várias ações dos indivíduos. Chamadas telefônicas, compras de passagem aérea, câmbio, transferência financeira, uso de cartão de crédito, etc. $\mathrm{O}$ que se pretenderia obter através da análise de um tal conjunto de informações? É seu conteúdo que interessa, ou é seu padrão de composição e acesso? Enquanto os conteúdos apontam para as pessoas, para os sujeitos no sentido singular da informação (conversou tal assunto, foi para tal país, trocou tantos dólares...), os padrões, por sua vez, nos remeteriam ao quê? Aos indivíduos como códigos digitais dentro de uma amostra específica? Há diferença entre viajar uma única vez ou vinte vezes em seis meses a um mesmo país? Esses parecem ser aspectos cruciais na mudança das estratégias que nos conduziram dos modelos tradicionais de disciplina aos modelos mais sofisticados de controle atuais.

Há que se notar um aspecto básico, o de que sociedades disciplinares e de controle estruturaram de forma diferente suas informações. No primeiro tipo de sociedade, teríamos uma organização vertical e hierárquica das informações. Neste caso, o problema do acesso à informação, por exemplo, confunde-se com a posição do indivíduo numa hierarquia, seja ela de função, posto, antiguidade, etc. Além disso, as informações parecem adequar-se à estratégia de compartimentalização que configura o dispositivo disciplinar. Dessa forma, cada instituição detém seu quinhão de informação, como algo que pertence ao seu próprio espaço físico. Há uma associação profunda entre o local, o espaço físico e o sentido de propriedade dos bens imateriais. Há uma intensa regulação dos fluxos imateriais no interior dos edifícios e entre eles, de tal maneira que a resposta à pergunta “onde está?" parece indicar ao mesmo tempo o lugar físico e a propriedade da informação.

Cabe lembrar que nos dispositivos disciplinares, como nos mostra Foucault (1998), há uma espécie de polarização entre a opacidade do poder e a transparência dos indivíduos. Lembremos da famosa imagem do panóptico. O poder, devido a sua situação privilegiada, se manteria fora do alcance dos indivíduos, enquanto estes últimos estariam numa situação de constante observação, sendo portanto transparentes aos seus olhos (Foucault, 1998; Rheingold, 2002). Numa tal situação, parece que a reivindicação fundamental seria: maior transparência do poder, para que possamos ver quem vive nos espiando e controlando.

Essa crença acabou alimentando uma série de reflexões sobre a suposta transparência que a web nos ofereceria, e sua conseqüente força diante dos obscurantistas que defendem os velhos esquemas de poder. Assim, poderíamos ter finalmente com a web a liberdade de expressão, o acesso às informações democratizado, etc. ${ }^{1}$ Claro que nada disso é desprezível, sendo mesmo algo que nos permite uma mobilidade sem precedentes. Mas, o que se passa, então, com o advento da sociedade de controle, que é predominantemente reticular, interconectada? Há uma mudança de natureza do próprio poder, que não é mais hierárquico, e sim disperso numa rede planetária, difuso. Isso pode significar que a antiga dicotomia opacidade-transparência não seja mais pertinente. Como diz Deleuze (1990), os anéis da serpente são mais complexos... O poder hoje seria cada vez mais ilocalizável, porque disseminado entre os nós das redes. Sua ação não seria mais vertical, como anteriormente, mas horizontal e impessoal. É verdade que a verticalidade sempre esteve associada à imagem de alguém: é o ícone que preenche o lugar do poder. Mas numa sociedade inteiramente axiomatizada, as instâncias de poder estão dissolvidas por entre os indivíduos, o poder não tem mais uma cara. Sua ação agora não se restringe apenas à contenção das massas, à construção de muros dividindo cidades, à retenção financeira para conter o consumo. Essas são estratégias que pertencem ao passado.

Hoje, o importante parece ser essa atividade de modulação constante dos mais diversos fluxos sociais, seja de controle do fluxo financeiro internacional, seja de reativação constante do consumo (marketing) para regular os fluxos do desejo ou, não esqueçamos, da expansão ilimitada dos fluxos de comunicação. Por outro lado, da mesma forma que o terrorismo é uma conseqüência do terror 
imposto pelo Estado, a ação não localizada dos hackers, produzindo disfunções e rupturas nas redes, parece ser o efeito que corresponde adequadamente aos novos modos de atuação do poder. Nenhuma forma de poder parece ser tão sofisticada quanto aquela que regula os elementos imateriais de uma sociedade: informação, conhecimento, comunicação. O Estado, que era como um grande parasita nas sociedades disciplinares, extraindo mais-valia dos fluxos que os indivíduos faziam circular, hoje está se tornando uma verdadeira matriz onipresente, modulando-os continuamente segundo variáveis cada vez mais complexas. Na sociedade de controle, estaríamos passando das estratégias de interceptação de mensagens ao rastreamento de padrões de comportamento...

\section{INTERCEPTAÇÃO DE MENSAGENS: SISTEMA ECHELON}

Boa parte do sistema atual de vigilância eletrônica global ainda é baseada na interceptação de mensagens. Esses sistemas são a conseqüência inevitável da invenção da rádio, e estão ligados à própria essência das telecomunicações. Assim como o rádio possibilitou a transmissão de mensagens para além dos continentes, do mesmo modo permitiu que qualquer um as escutasse. Não há dúvidas de que foi a invenção da rádio que deu uma nova importância à criptografia, a arte e a ciência de criar códigos secretos. Ela estaria na origem do mercado de interceptação de sinais.

Um dos sistemas mais famosos de vigilância planetária desenvolveu-se principalmente em decorrência dos conflitos da Segunda Guerra Mundial. Duncan Campbell (2001), autor de um relatório para o Parlamento Europeu sobre o sistema Echelon, conta que durante a Segunda Grande Guerra, enormes organizações de decodificação pertencentes às forças aliadas, na Inglaterra e nos EUA, leram e analisaram centenas de milhares de sinais alemães e japoneses. Foi nesse período que entrou em funcionamento uma rede de escuta planetária chamada Ukusa, um acordo firmado em 1947 entre os governos dos EUA, Inglaterra, Canadá, Austrália e Nova Zelândia. Num esforço de vigilância jamais visto, a Agência de Segurança Nacional dos Estados Unidos - NSA, criou um sistema global de espionagem chamado Echelon (dentro do acordo Ukusa), que hoje tenta capturar e analisar virtualmente todas as chamadas telefônicas e mensagens de fax, email e telex enviadas de qualquer ponto do planeta. O sistema Echelon é muito simples em seu desenho: esta- ções de interceptação de sinais em todo o mundo capturam todo o tráfego de comunicações via satélite, microondas, celular e fibra ótica, processando essas informações em computadores de alta capacidade. Isso inclui programas de reconhecimento de voz, programas de reconhecimento de caracteres, procura por palavras-chave e frases no dicionário Echelon, que capacitam o computador a marcar as mensagens, gravá-las e transcrevê-las para futuras análises.

O projeto Echelon enquadra-se numa perspectiva de controle baseada na interceptação de sinais e de comunicação, e na quebra de seu código para se chegar a seu conteúdo. Trata-se, portanto, de vasculhar o conteúdo de mensagens transmitidas por diversos meios e trocadas pelas mais diferentes instâncias, como indivíduos, governos, organizações internacionais, organismos privados e comerciais.

Nos anos 40, o primeiro foco das operações do Echelon foi a espionagem militar e diplomática. Já nos anos 60, na esteira do crescimento do comércio internacional, a interceptação de informações acabou incluindo os campos econômico e científico. Só recentemente a atenção dessa rede de vigilância planetária voltou-se para o tráfico de drogas, a lavagem de dinheiro, o terrorismo e o crime organizado. O governo Clinton, por exemplo, teria apoiado, em 1993, a atuação das operações de interceptação no plano comercial. É significativa a lista apresentada por Campbell das empresas americanas que teriam vencido concorrências graças à intervenção do governo norte-americano e com a ajuda de informações obtidas pela NSA (o projeto Sivam, do Brasil, por exemplo, encontra-se entre os citados). Já o atual governo Bush tem trabalhado incansavelmente na interceptação de informações das redes terroristas e do crime organizado.

Deve-se notar, no entanto, que nos últimos 15 anos a evolução tecnológica da rede Echelon deixou de estar adiante de seu tempo, sendo hoje alcançada pelas redes industriais e acadêmicas com seus equipamentos de última geração. O chamado "ciclo da informação", composto pela interceptação, coleta, seleção, tratamento e entrega das mensagens relevantes aos "clientes", que ainda é cumprido quando se trata de transmissões em alta freqüência, em ondas curtas, cabos submarinos, satélites de comunicação ou Internet, agora tem dificuldades com as redes de fibra ótica de alta capacidade e com redes de satélites do tipo Iridium. Além disso, como afirma Campbell (2001), “os organismos de espionagem dos sinais reconhecem que a longa batalha contra a criptografia 
civil e comercial foi perdida. Uma comunidade acadêmica e industrial sólida está agora voltada para a criptografia e a criptologia. Reconhecendo esse fato, os EUA liberaram em janeiro de 2000 seu serviço de exportação de métodos de criptografia, permitindo a cidadãos e a empresas não-americanas comprar e utilizar produtos de codificação potentes" (tradução do autor).

Isso significa que, de algum modo, a percepção sobre a prática da interceptação de mensagens está mudando, e não porque se trate apenas de aprimorar as técnicas de criptografia, mas também de mudar a forma de abordagem do controle. Afinal, apesar de todo o poder do projeto Echelon e de vários outros do mesmo gênero, os ataques terroristas continuaram passando sem interceptações significativas. Por conta disso, atualmente, dezenas de empresas trabalham para o Departamento de Defesa dos EUA, muitas delas localizadas no Vale do Silício. Duas das mais importantes são AST e The Ideas Operation, dirigidas por antigos funcionários do alto escalão da NSA. As duas trabalham no desenvolvimento de softwares de filtragem, tratamento de dados, análise de fac-símiles, análise do tráfego de informações, reconhecimento de palavras-chave, análise por temas, sistemas de reconhecimento de voz, etc. São empresas que possuem pleno domínio das novas técnicas desenvolvidas para rastrear as mais diversas ações dos indivíduos e, a partir disso, construir padrões de comportamento.

\section{A QUESTÃO DA VIGILÂNCIA}

O projeto Echelon representa, portanto, um caso exemplar, pois pode ser considerado o último grande descendente dos sonhos de uma sociedade disciplinar e de sua concepção de vigilância, sendo ao mesmo tempo o ancestral de nossa sociedade de controle. Isso porque ele enfrentou a transição nos sistemas de comunicação do planeta, provocada pela revolução da informática.

Há aqui uma modificação no sentido de vigilância, que passa da sociedade disciplinar à sociedade de controle. $\mathrm{Na}$ primeira, a idéia de vigilância remetia ao confinamento e, portanto, à situação física que caracterizava as preocupações dessa sociedade. O problema era o movimento físico dos indivíduos, seu deslocamento espacial. Vigiar era, basicamente, regular os passos das pessoas, era olhar. Com a explosão das comunicações, uma nova figura ganha força: a vigilância das mensagens, do trânsito de comunicações. É a época dos espiões, dos agentes secretos. Ultrapassamos Sherlock Holmes, que seguia os índices e pistas dos movimentos dos suspeitos, e alcançamos 007, envolvido em tramas internacionais via satélite. Vigiar passou a significar, sobretudo, interceptar, ouvir, interpretar.

Com a explosão da web alguma coisa está mudando. Devido à nova forma como as informações são estruturadas, em rede e reproduzidas em $n$ pontos, acabamos gerando uma nova forma de vigilância, que se preocupa em saber de que modo essas informações estão sendo acessadas pelos indivíduos. Parece que o mais importante agora é a vigilância sobre a dinâmica da comunicação não apenas entre as pessoas, mas sobretudo entre estas e as empresas, os serviços on-line, o sistema financeiro, enfim, todo o campo possível de circulação de mensagens. O que parece interessar, acima de tudo, é como cada um se movimenta no espaço informacional. Isso parece dizer tanto ou mais sobre as pessoas do que seus movimentos físicos ou o conteúdo de suas mensagens. A vigilância constante sobre as trilhas que os indivíduos deixam na web, por exemplo, tornou-se objeto de inúmeras discussões e especulações. Afinal, quem somos nós? Para onde vamos, o que fazemos, o que dizemos? Ou o que pensamos? O modo como nos deslocamos por entre informações revela muito do como pensamos, pois mostra como associamos elementos díspares ou semelhantes.

O tracking generalizado nos chama a atenção. Há uma espécie de vigilância disseminada no social, já que todos podem, de certa forma, seguir os passos de todos. O controle exercido é generalizado, multilateral. As empresas controlam seus clientes; as ONGs controlam as empresas e os governos; os governos controlam os cidadãos; e os cidadãos controlam a si mesmos, já que precisam estar atentos ao que fazem.

\section{A BUSCA POR PADRÕES DE COMPORTAMENTO}

Como lembra o matemático e sociólogo francês Michel Authier, "o sentido de um documento está menos nele próprio do que nas pessoas que o consultam". ${ }^{2}$ Isso significa que os vários sentidos de um documento vêm sobretudo dos interesses de quem o consulta e que, dessa forma, no sentido inverso, o mapeamento da afluência de grupos de usuários a um determinado tipo de informação pode revelar muito sobre cada indivíduo e seus pares. Estamos falando aqui da importância da construção do perfil do usuário, termo que com o advento da web passou a ter um significado e uso mais amplo do que o atribuído pelos departamentos de RH. $\mathrm{Na}$ Internet, não temos uma identidade, mas um perfil ${ }^{3}$ 
(Costa, 2002). Com a explosão da web, no início dos anos 90, muitos foram os sites que começaram a utilizar a declaração do perfil de cada usuário para uma série de operações: oferta de produtos, de notícias, de programação nos veículos de mídia, endereçamento de perguntas, encontro de parceiros, etc. Já na virada do milênio, o desenvolvimento da tecnologia de agentes inteligentes permitia mapear os perfis de usuários da web de maneira dinâmica, acompanhando suas atividades e aprendendo sobre seus hábitos. Essas novas ferramentas trabalham hoje não apenas orientadas por palavras-chave, mas também relacionando as consultas realizadas por todos os usuários em sua base de dados. Isso é feito com a finalidade de se encontrar padrões que possam auxiliar o próprio sistema na sua relação com os usuários, antecipando a oferta de produtos e serviços (Costa, 2002).

Um dos casos mais interessantes e conhecidos desse tipo de tecnologia que funciona no ciberespaço é o que auxilia as pessoas a selecionarem filmes, livros, programas televisivos e shows a partir, exclusivamente, da correlação entre os gostos pessoais de vários usuários (Maes, 1997). O site mais conhecido que possui esse tipo de agente inteligente é o da livraria Amazon.com. Todos aqueles que já o consultaram a procura de um título, tiveram a oportunidade de receber como sugestão do site uma lista de quatro a seis outros títulos que também interessaram a outras pessoas que compraram o livro ou produto em questão. Essa lista é produzida a partir do rastreamento feito por um agente inteligente que constrói um perfil dinâmico da pessoa, tendo como referência o que ela adquire através do site (como livros, CDs, vídeos, brinquedos, etc.). Dessa forma, é possível apresentar uma lista de sugestões ao usuário, com base naquilo que outras pessoas de perfil semelhante ao dele compraram. Trata-se da construção de padrões de interesse, a partir dos quais indivíduos que compartilham os mesmos gostos funcionam como um padrão para indicações interessantes que podem ser cruzadas dentro de um mesmo grupo (Costa, 2002).

Essa técnica de rastreamento das atividades dos usuários é usada também em sites como o Abuzz.com, do New York Times, uma comunidade virtual que funciona em torno de perguntas e respostas enviadas por seus participantes. $\mathrm{O}$ agente inteligente de Abuzz acompanha cada usuário em suas atividades, construindo um perfil de acordo com suas perguntas e respostas, com os temas tratados, com a freqüência de suas ações, etc. Isso permite à ferramenta endereçar adequadamente perguntas para aqueles que mais se aproximam do perfil dos que podem responder.
Um outro exemplo do que está sendo dito, mas agora fora do campo da Internet, é o da TV digital interativa. A empresa líder no mercado mundial, OpenTV, desenvolveu um pequeno agente inteligente que é capaz de traçar a silhueta de uma pessoa através de sua ação cotidiana sobre o controle remoto. Nesse caso, o agente constrói a silhueta rastreando a ação pura e simples do telespectador junto ao televisor. Ele atua registrando e associando várias coisas automaticamente: os momentos em que a pessoa assiste a TV, os programas que ela assiste e, o mais importante, o ritmo de mudança de canais. De posse desses dados, o agente consegue estabelecer, para uma família usual (quatro ou cinco pessoas), os hábitos televisivos dos adultos homens, dos adultos mulheres e das crianças. Ou seja, ele constrói um conjunto de padrões de comportamento a partir das ações dos próprios usuários. Isso significa que não há nenhuma tabela a priori de padrões para ele se orientar. Com o tempo, ele consegue reconhecer cada um no momento mesmo em que liga a TV, e pode assim lhe oferecer alguma sugestão (Costa, 2002).

\section{RASTREANDO O PLANETA - O PROJETO TIA}

É toda essa tecnologia que vem sendo agora incorporada pelos mais recentes projetos que alimentam a sociedade de controle. Um exemplo importante, e recente, é o projeto americano TIA - Total "Terrorism" Information Awareness, que propõe abertamente capturar a "assinaturainformação" das pessoas. Dessa forma, o governo poderia rastrear terroristas potenciais e criminosos envolvidos em tipos de crimes contra o Estado de difícil detecção. ${ }^{4}$

A estratégia do projeto é rastrear indivíduos, coletando tanta informação quanto possível e usando softwares inteligentes e análise humana para detectar suas atividades potenciais. O projeto está investindo no desenvolvimento de uma tecnologia revolucionária para a armazenagem de uma quantidade enorme de todo tipo de fonte de informação, associando essas múltiplas fontes para criar um "grande banco de dados, virtual e centralizado". A diferença aqui é que essa grande memória seria alimentada a partir das transações contidas em diversos bancos de dados, tais como os registros financeiros, registros médicos, registros de comunicação, registros de viagens, etc. É com esse material que o rastreamento das informações será possível, e com ele a construção de padrões e associações entre os dados. O reconhecimento de padrões está diretamente ligado à mudança nos métodos de controle das ações individuais. 
Ora, aquilo que na web é a construção de um perfil dinâmico de usuários com fins comerciais, que serve para alimentar a sociedade de controle light do marketing, agora no TIA passa a ser a construção do perfil total, que será o resultado do cruzamento das ligações telefônicas de um indivíduo (sua origem, destino, data e duração), as despesas efetuadas em cartões de crédito (quanto, onde, quando) e, a partir destas, as operações comerciais mais diversas. O que o projeto almeja, com esse esforço, é a produção de uma visão dos padrões de comportamento de amostras da população. O objetivo básico do projeto é auxiliar analistas a compreender e mesmo prever uma ação futura, no caso uma ação terrorista. Mas o mais importante é que, diferentemente da estratégia de interceptação de mensagens que já conhecemos no Echelon, onde o que se procura de forma direta são conteúdos específicos associados a pessoas específicas, no TIA o processo seria em princípio indireto, pois é pelo negativo dos padrões que se intercepta um comportamento suspeito. E com a implantação de um tal projeto, chegamos definitivamente na modulação contínua da sociedade de controle de que nos fala Deleuze, pois deixamos de olhar para as informações como associadas a indivíduos, e sim como relacionadas entre si dentro de um quadro maior. É justamente essa amostra ou conjunto de dados que deve ser modulado.

\section{DA IDENTIDADE AO CÓDIGO}

Quando assinamos um documento, um cheque, estamos imprimindo ali nossa identidade. A assinatura, historicamente, sempre foi o signo maior da identidade pessoal. $\mathrm{O}$ $\mathrm{CPF}$, que é o número de registro numa massa, assegura ao indivíduo seu estatuto de existente regulamentado. Com a sociedade de controle, a assinatura é posta em dúvida, deve ser verificada, e o CPF é usado para checar seus movimentos financeiros. Mas o controle inventa ainda seus próprios dispositivos: o código e a senha no lugar da assinatura. A diferença é que a assinatura é produzida pelo indivíduo, e o código é produzido pelo sistema, para o indivíduo: é dito intransferível, pois, dado que foi feito por você, como sua marca própria e singular, pode ser passado a outro. É interessante notar que, enquanto nos cartões de crédito, a operação de débito automático requer o uso de senha, a operação de crédito, pelo menos por enquanto, requer a assinatura (além do número do cartão). A senha é checada na hora porque estamos acessando o sistema, ao passo que a operação de crédito é realizada apenas posteriormente. Acontece que, muitas vezes, mesmo sem motivo aparente, sua senha é recusada! Não há nada a fazer, você não é mais você para aquela operação, mesmo que continue sendo você para pagar de outra forma. Você é você para algumas coisas, e não é você para outras... porque sua senha num sistema não foi aceita. Esse é o conceito de modulação universal de que nos fala Deleuze, onde o indivíduo passa a ser divisível, ora podendo, ora não podendo. Na verdade, a modulação ocorre sobre um conjunto ou grupo de códigos, o indivíduo podendo ou não ter acesso a um serviço liberado pelo sistema (overbooking, rodízio de carros, sistema pay-perview, acesso a provedor...).

Também do ponto de vista da geografia, o código vem substituindo gradativamente a identidade. As noções de identidade e corpo físico sempre estiveram associadas uma a outra. Com o advento do espaço urbano partilhado administrativo, há a emergência de um duplo do corpo: o sistema numérico que nos identifica. Assim, o telefone, o cartão de crédito, o número da previdência, etc. permitem, cada vez mais, expandir ou restringir nossa mobilidade no espaço físico. Hoje já temos a clareza de estarmos vivendo sob um novo conceito: o de ser humano em rede (Boullier, 2000).

Numa sociedade disciplinar, atrelada ao espaço físico, um indivíduo era referenciado por seu endereço postal, que remetia a um lugar físico que não era mais que um ponto numa rede geográfica de longa duração. Hoje, um habitante se define como inscrito numa rede variável, onde a prova de domicílio não é mais o título de propriedade ou o pagamento de aluguel, mas a fatura de água, de eletricidade ou gás, de telefone, etc. É nossa inscrição nessas redes, nosso estatuto de consumidor de fluxos técnicos que serve como prova jurídica de nosso pertencimento espacial (Boullier, 2000). Somos humanamente definidos como membros de múltiplas redes.

As redes sociotécnicas são muitas: água, transportes, comércio, telecomunicação, telefonia, comunicação, TV, jornal, computação, web, portáteis. Estamos dentro de muitas redes simultaneamente e permanentemente. Always on and everywhere (Rheingold, 2002). Na cidade digital, em casa ou no trabalho, pelo fato de essas redes estarem interconectadas, podemos acessar múltiplos serviços sem a necessidade de nos deslocarmos. Temos entrega de produtos, pagamentos tipo homebanking, serviços públicos, trabalho e muitas outras coisas possíveis pelo fato de que a cidade está digitalizada. Por outro lado, em trânsito, temos acesso à cidade digital via cartões multiserviços, terminais eletrônicos, aparelhos portáteis. Uma nova lógica, 
portanto, está em curso, no que diz respeito aos deslocamentos e acessos.

Não esqueçamos, no entanto, que essa ubiqüidade dos seres só é possível por causa do dinheiro eletrônico. Ele representa mais uma mutação do capitalismo, pois se o dinheiro papel é caro e sem controle em sua circulação, o dinheiro eletrônico, além de reduzir os custos, acaba gerando mais controle sobre os indivíduos e a circulação do capital. O papel moeda é anônimo, o dinheiro eletrônico não. É o caso do imposto CPMF criado no Brasil, através do qual é possível controlar toda a circulação financeira digital do país.

Outro aspecto fundamental da modulação na geografia é o monitoramento da localização de portáteis. Isso já é uma realidade para usuários de celulares ou palms. Eles funcionam através do sistema GPS - Global Positioning System e de redes celulares. ${ }^{5}$ Segundo Pfeiffer (2003) "os consumidores terão à sua disposição um conjunto de tecnologias trabalhando juntas para assegurar que alguém ou alguma rede sempre saiba onde você está, o que você está procurando e aonde você precisa chegar". Pense nisso, diz ele, "como um Big Brother consentido - um irmão mais velho com bom senso de direção”. Em princípio, essa localização funcionaria para que os usuários pudessem solicitar serviços diversos, como o restaurante mais próximo, cinemas, estações de metrô, mapas e informações sobre a área em que se encontra. O serviço de emergência, 911, já teria inclusive uma lei de obrigatoriedade de localização automática, para facilitar a chegada de socorro. Mas os usuários podem também optar por receber mensagens de marketing. Com isso, estando numa área próxima a um certo comerciante, é possível receber uma promoção exclusiva, personalizada, pelo simples fato do usuário se encontrar próximo do ponto de venda.

Bem, se somarmos a isso todos os sistemas de vigilância por câmeras, disponíveis para os departamentos de trânsito, estaremos finalmente desembarcando no mundo de Minority Report, onde a grande questão não é simplesmente antecipar os crimes do futuro, mas estabelecer essa modulação contínua, no presente, de todos os comportamentos, com os indivíduos não sendo mais que pontos localizáveis numa série de redes que se entrecruzam. Assim, só resta aos usuários controlar todo o tempo as informações pessoalmente identificáveis que eles estão fornecendo ao sistema continuamente. Como nos alerta Deleuze (1990), "diante das próximas formas de controle incessante em meio aberto, é possível que os mais rígidos sistemas de clausura nos pareçam pertencer a um passado delicioso e agrádavel”.

\section{NOTAS}

1. Pierre Lévy (2002) é um dos que mais defende essa posição, de que a transparência da $w e b$ seria uma forma de resistência ao poder.

2. Michel Authier é conhecido por seus trabalhos filosóficos com Pierre Lévy e também por seus estudos matemáticos, sobretudo pela invenção do algoritmo do mecanismo de busca por proximidade chamado Umap e das Árvores de Conhecimentos.

3. Tracking de cookie ou número IP - Internet Protocol.

4. Ver dois sites importantes para informações sobre as ações de controle dos EUA: < http://cryptome.org $>$ e $<$ http://www.epic.org/privacy/ profiling/tia/ $>$.

5. O Departamento de Defesa dos Estados Unidos lançou o GPS em 1978 para possibilitar o bombardeio com armas de precisão.

\section{REFERÊNCIAS BIBLIOGRÁFICAS}

BOULLIER, D. Processeur et réseau: les nouveaux formats de l'être urbain. In: SANDOVAL, V. (Org.). La Ville Numérique. Paris: Hermes, 2000. p.171-190.

CAMPBELL, D. Surveillance Electronique Planetaire. Paris: Allia, 2001.

COSTA, R. A cultura digital. São Paulo: Publifolha, 2002. (Coleção Folha Explica).

DELEUZE, G. Pourparlers. Paris: Les Éditions de Minuit, 1990.

FOUCAULT, M. Vigiar e Punir. Petrópolis, RJ: Vozes, 1998.

HARDT, M. La société mondiale de contrôle. In: ALLIEZ, E. (Org.). Gilles Deleuze, une vie philosophique. Paris: Synthélabo, 1998. p.359-376.

LESSIG, L. Code and other laws of cyberspace. New York: Perseus, 1999.

LÉVY, P. Cyberdemocratie. Paris: Odile Jacob, 2002.

MAES, P. Agents that reduce work and information overload. In: BRADSHAW, J. Software Agents. Cambridge, MA: MIT Press, 1997.

PFEIFFER, E. Technology review. Folha de S.Paulo, São Paulo, 22 out. 2003. Folha Informática.

RHEINGOLD, H. SmartMobs. The Next Social Revolution. Cambridge, MA: Perseus, 2002.

SHAPIRO, A.L. The Control Revolution. New York: Public Affairs, 1999.

TIA. Electronic Privacy Information Center. Disponível em: $<$ http://www.epic.org/privacy/profiling/tia/>.

Rogério da Costa: Filósofo, Professor na Pós-Graduação em Comunicação e Semiótica da PUC-SP, Coordenador do Laboratório de Inteligência Coletiva (rogcosta@pucsp.br, www.pucsp.br/linc). 